\title{
Collaboration for rare disease drug discovery research
}

\section{[version 1; peer review: 2 approved]}

\author{
Nadia K. Litterman1, Michele Rhee2, David C. Swinney³, Sean Ekins (iD) 1,4-7 \\ ${ }^{1}$ Collaborative Drug Discovery, Inc., Burlingame, CA, 94010, USA \\ ${ }^{2}$ National Brain Tumor Society, Newton, MA, 02458, USA \\ ${ }^{3}$ Institute for Rare and Neglected Diseases Drug Discovery (iRND3), Mountain View, CA, 94043, USA \\ ${ }^{4}$ Collaborations in Chemistry, Fuquay Varina, NC, 27526, USA \\ ${ }^{5}$ Phoenix Nest Inc., Brooklyn, NY, 11215, USA \\ ${ }^{6}$ Hereditary Neuropathy Foundation, New York, NY, 10016, USA \\ ${ }^{7}$ Hannah's Hope Fund, Rexford, NY, NY 12148, USA
}

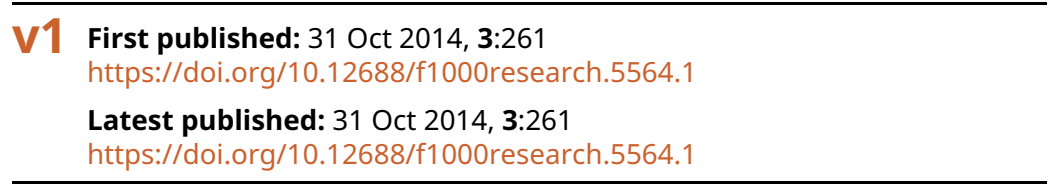

\section{Abstract}

Rare disease research has reached a tipping point, with the confluence of scientific and technologic developments that if appropriately harnessed, could lead to key breakthroughs and treatments for this set of devastating disorders. Industry-wide trends have revealed that the traditional drug discovery research and development (R\&D) model is no longer viable, and drug companies are evolving their approach. Rather than only pursue blockbuster therapeutics for heterogeneous, common diseases, drug companies have increasingly begun to shift their focus to rare diseases. In academia, advances in genetics analyses and disease mechanisms have allowed scientific understanding to mature, but the lack of funding and translational capability severely limits the rare disease research that leads to clinical trials. Simultaneously, there is a movement towards increased research collaboration, more data sharing, and heightened engagement and active involvement by patients, advocates, and foundations. The growth in networks and social networking tools presents an opportunity to help reach other patients but also find researchers and build collaborations. The growth of collaborative software that can enable researchers to share their data could also enable rare disease patients and foundations to manage their portfolio of funded projects for developing new therapeutics and suggest drug repurposing opportunities. Still there are many thousands of diseases without treatments and with only fragmented research efforts. We will describe some recent progress in several rare diseases used as examples and propose how collaborations could be facilitated. We propose that the development of a center of excellence that integrates and shares informatics resources for rare diseases sponsored by all of the stakeholders would help foster these initiatives.

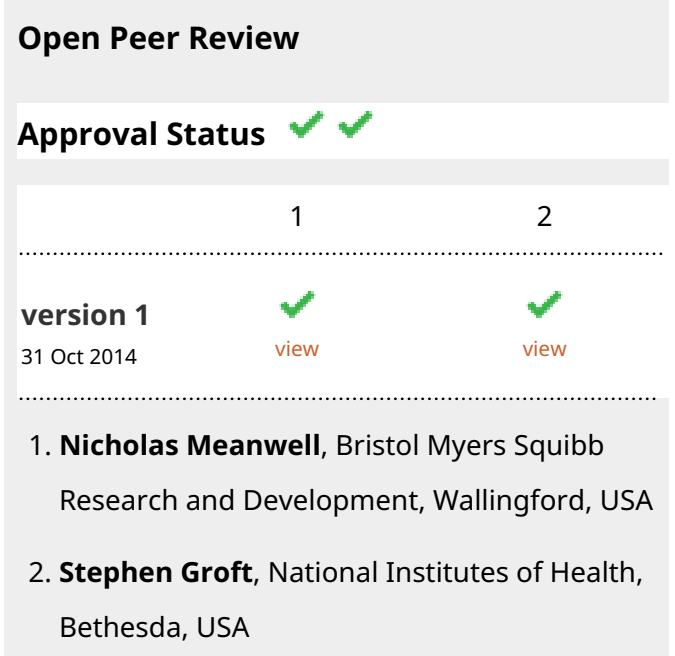

Any reports and responses or comments on the article can be found at the end of the article. 
Keywords

rare disease, patient advocacy, drug discovery , Twitter

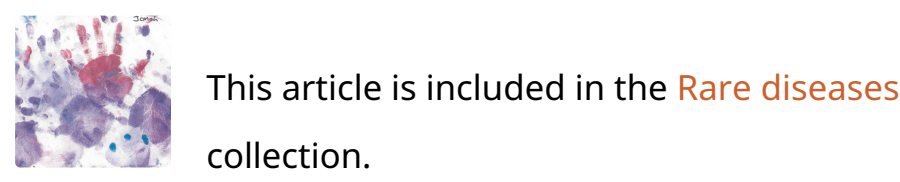

Corresponding authors: Nadia K. Litterman (nadia@collaborativedrug.com), Sean Ekins (ekinssean@yahoo.com)

Competing interests: S.E. works for Collaborations in Chemistry, and consults for Collaborative Drug Discovery Inc. as well as rare disease groups including the Hereditary Neuropathy Foundation, Hannah's Hope Fund and Phoenix Nest. N.K.L. works for Collaborative Drug Discovery Inc. M.R. works for National Brain Tumor Society. D.C.S. works for the Institute for Rare \& Neglected Diseases Drug Discovery.

Grant information: The author(s) declared that no grants were involved in supporting this work.

Copyright: ( 2014 Litterman NK et al. This is an open access article distributed under the terms of the Creative Commons Attribution License, which permits unrestricted use, distribution, and reproduction in any medium, provided the original work is properly cited. Data associated with the article are available under the terms of the Creative Commons Zero "No rights reserved" data waiver (CC0 1.0 Public domain dedication).

How to cite this article: Litterman NK, Rhee M, Swinney DC and Ekins S. Collaboration for rare disease drug discovery research [version 1; peer review: 2 approved] F1000Research 2014, 3:261 https://doi.org/10.12688/f1000research.5564.1

First published: 31 Oct 2014, 3:261 https://doi.org/10.12688/f1000research.5564.1 


\section{Introduction}

Although each rare disease affects less than 200,000 individuals in the United States, in aggregate, rare diseases affect 6-7\% of the population $^{1}$. As less than $10 \%$ of these patients can be presently treated, this remains a very large unmet medical need ${ }^{2}$. According to the National Organization for Rare Disorders (NORD), there are only 250 treatments for the nearly 7,000 rare disorders, impacting nearly 30 million Americans. Eighty percent of these diseases have a genetic origin ${ }^{1,3}$. Most rare diseases are caused by mutations in a single gene, such as an enzyme deficiency (like $\alpha$-galactosidase A in Fabry's Disease). Other diseases, such as Charcot-Marie-Tooth (CMT), have multiple genetic causes ${ }^{4}$. In either case, the knowledge of the genetic basis of the disease can be quite illuminating and lead to therapeutic development efforts ${ }^{3}$.

In metabolic disorders such as the lysosomal storage diseases, the development of biologics such as enzyme replacement therapy has been quite fruitful. In rare cancers, the knowledge of mutated kinases has led to the development of specific, potent small molecule inhibitors ${ }^{5,6}$. There are many diseases with approved drugs developed by a knowledge of genetics such as: myelofibrosis, non-small cell lung cancer (NSCLC), late stage melanoma, chronic myelogenous leukemia (CML), Gaucher's disease, Pompe's disease, hyperphenylalaninemia, Hunter syndrome, mucopolysaccharidosis (MPS) VI, MPS I, Fabry's disease, Type I tyrosinemia, hyperammonemia due to N-acetylglutamate synthase (NAGS) deficiency, cystic fibrosis, hereditary angioedema (HAE), cryopryin-associated periodic syndromes, and paroxysmal nocturnal hemoglobinuria ${ }^{3}$.

Developing novel therapeutics is always a risky and difficult endeavor ${ }^{7,8}$, and the process of drug discovery for rare diseases is marked by unique challenges. Rare diseases represent an example of the power of individualized therapies, but under the current paradigm the trade-off is that these are incredibly expensive $e^{9,10}$. So there is an urgent need to discover ways to develop therapies more cost-effectively ${ }^{11}$. Using our perspectives as rare disease researchers and patient advocates with experience of facilitating collaborations, we will use the diseases we have most knowledge of to outline the challenges that we see and offer some proposed solutions in this opinion article.

\section{Getting connected}

Rare diseases, by definition, have very small numbers of patients (sometimes in the low tens to hundreds) that are often dispersed and disconnected globally. This is problematic for understanding the natural history of the disease, identifying the underlying mechanisms, and recruiting patients for clinical trials ${ }^{3}$. Before a therapy can be developed, the natural history needs to be understood so that the clinical trials can attempt to show a positive outcome with the disease in question. Despite the inherent difficulties, recent trends and technological developments, including in genomics, collaboration, and even social media, can be harnessed to the advantage of rare disease patients and researchers.

The connectivity and network-building enabled by the internet is especially important for rare disease patients and caregivers during diagnosis and treatment. Even well-informed individual physicians are unlikely to have experience with all given rare conditions, making diagnoses challenging. Despite the importance for support and knowledge sharing, it is extremely unlikely for rare disease patients to find one another through traditional methods like face to face networking, conferences, newspaper and magazine articles, etc., especially since the Health Insurance Portability and Accountability Act (HIPAA) privacy rules make it difficult ${ }^{12,13}$ to share information. Recent technological advancements have helped to reduce the barriers for doctors, caregivers, and patients to reach out to find one another. Social network sites such as Sermo ${ }^{14}$ and Doximity ${ }^{15}$ enable physicians to crowdsource a diagnosis. In addition, patients can find one another through websites and social media. For example, many rare disease groups set up public or private Facebook pages. Some are totally open and write regular blog posts to communicate their activities and goals, or what they have done to increase awareness, fund-raise, or look for a cure. In other cases they may be private sites for caregivers to use them to share their experiences. Both approaches enable families with very rare diseases to connect and then build momentum from there ${ }^{16,17}$. Many rare disease advocates are also users of Twitter as a tool to highlight articles of interest, promote their fundraising events, or just share their experiences (Table 1). Overall, this increased connectivity benefits patients, trying to identify the source of their symptoms and understand their recent diagnosis. In addition, such connected patient networks can also lead to key research breakthroughs, such as defining the genetic origin of the disease, understanding the natural history, defining biomarkers, and recruiting patients for clinical registries, natural history studies and clinical trials. A useful side effect of this social networking is to raise the overall level of awareness amongst the population that was previously not familiar with rare diseases.

\section{The role of patient advocacy organizations}

Historically, industrial sponsors of research and clinical trials see the rare disease space as riskier, and less profitable than more common diseases. The perception around profit has shifted as rare disease blockbuster drugs (such as Vertex's Kalydeco ${ }^{\mathrm{TM}}$ for cystic

\section{Table 1. List of rare disease related Twitter users. (Also see http://www.totalbiopharma. com/2013/07/01/top-50-social-media-influencers- orphan-drugs-rare-disease/ and http://moderators. rareconnect.org/social-media-case-studies/ raredisease-patient-advocates-follow-these-25- twitter-accounts/)}

\begin{tabular}{|l|l|}
\hline @RareDR & @alsadvocacy \\
\hline @RareDiseases & @CheckOrphan \\
\hline @SDFatPhRMA & @eurordis \\
\hline @savingcase & @AfternoonNapper \\
\hline @JJB4CURE & @HurtBlogger \\
\hline @RareVoices & @bensfriends \\
\hline @RareDayUS & @alanROYGBIV \\
\hline @FMDChat & @_chrisco \\
\hline @ncats_nih_gov & @CureTheProcess \\
\hline @ORDR & @michelerhee \\
\hline @GlobalGenes & @lisamjarvis \\
\hline
\end{tabular}


fibrosis) make headlines. Still, key decision-makers within biopharmaceutical companies continue to be hesitant about pursuing rare disease indications due to the perceived risk. When the average drug costs $\$ 500$ million- $\$ 1$ billion (or more) and takes $15-20$ years to develop ${ }^{7,8}$, companies want to reduce the likelihood of failure and increase the potential revenue as much as possible. Hence the rationale behind rare disease drugs that cost upwards of $\$ 100,000$ per year. To be simplistic, the calculation considers whether the amount of money spent to get a drug to market will be less than the amount of money received in revenue over the lifetime of the patent exclusivity of the drug. The equation tends to come out on the wrong side for rare diseases, in large part because many of the attempts to get orphan drugs to market have failed, as evidenced by the lack of launched drugs. These failures increase the perception of riskiness of the space, which means that, at a minimum, companies are less likely to invest in programs focused on a rare disease.

One approach to solving this catch-22 problem is for patient advocacy groups to collaborate with academia, government, not-for profits and biopharmaceutical companies to increase incentives for investment in rare-disease-specific programs. Patient advocacy organizations play a role ${ }^{9,18,19}$ here because they can be uniquely strategic and creative to reduce risk, bring patients together for researchers and drive research forward.

\section{Reducing financial risk of investment}

At a base level, risk can be reduced if the cost of entering the disease area can be lowered, reducing the initial financial risk. When a company is deciding whether to pursue a specific indication for a disease, it is competing against others that may have existing preclinical models and clinical trial networks. The investment required is therefore often higher in rare diseases because the infrastructure does not exist. The barrier to entry can be mitigated through the support of and collaboration with disease-specific patient advocacy groups. Large organizations such as the Michael J. Fox Foundation for Parkinson's Disease Research and the Cystic Fibrosis Foundation have used a modified venture philanthropy model. This allows them to invest in and provide research grants to biotechnology companies who have designated programs in their specific disease areas. These investments and grants become true collaborations over time as these large patient advocacy groups provide disease expertise, access to key opinion leaders and patients, and clinical trial recruitment support. The key word here is time. These collaborations can last over a decade. Obviously, however, not all rare disease groups have the financial resources to invest the funding required to significantly reduce risk which at this level is likely in the \$10-100 millions range. Also, many groups are trying to discover therapies in a shorter time if possible. However, patient groups do not have to invest at this level to have an impact. Smaller investments in the low tens of thousands of dollars can have an impact in funding science ${ }^{9}$, providing the seed funding to develop an assay or animal model or even make a compound for testing. These efforts may more frequently be targeted to academia as long as the overhead costs can be kept to a minimum or avoided.

Brain cancer offers an example of where a company was able to spread the financial risk across a number of patient advocacy groups. Tocagen applied for and received research grants from three major brain tumor patient advocacy groups: National Brain Tumor Society, Accelerate Brain Cancer Cure and American Brain Tumor Association. Although the financial support was helpful, the company also benefited by having the support of these patient advocacy organizations as it recruited for clinical trials. Typically, because of the small patient population numbers, clinical trial recruitment is a huge issue in rare disease clinical trials, but Tocagen has not suffered the traditional patient recruitment problems.

\section{Reducing regulatory risk}

Other collaborative approaches that do not require as much financial outlay can also be successful at encouraging companies to build or to further develop specific programs. These are typically more policy- and advocacy-based and are often areas in which only patient advocacy groups or other not-for-profits can lead. Existing policies that increase incentives to discover new medical entities for rare diseases include the Orphan Drug Act, pediatric priority review vouchers, and extended patent exclusivity upon the inclusion of a pediatric indication.

Patient advocacy groups ${ }^{18}$ can also use their passion and experience to clarify some of the ambiguity in the regulatory environment for rare disease drug evaluations. Because there have been so few successes in the orphan drug space, drug companies have limited precedents to follow as they design their clinical trials and navigate the Food and Drug Administration (FDA). Typically, the FDA speaks to trial sponsors only within the context of a specific application, which is less of an issue when there have been recent or multiple approvals in a disease because the trial design and endpoints are clear. Companies will err on the conservative side and design trials with larger numbers of patients using endpoints that often take longer (for example, using overall survival instead of a surrogate endpoint).

One approach to clarifying this regulatory uncertainty is for the patient advocacy community to collaborate with key stakeholders to have open discussions about trial design and endpoints. For example, the Jumpstarting Brain Tumor Drug Discovery Coalition (comprised of the National Brain Tumor Society, the Society for Neuro-oncology, the Musella Foundation, and Accelerate Brain Cancer Cure) has hosted two workshops to discuss alternative and surrogate endpoints for clinical trials. FDA staff, trial sponsors, clinicians and scientists, clinical trial designers, and patients have all been actively involved in working with the patient advocacy coalition to identify endpoints and trial designs that will reduce the time and money required to run a clinical trial in brain cancer. Although the work is still ongoing, the FDA has pointed to this collaboration as an example for other patient advocacy groups to follow, and trial sponsors have enthusiastically participated. Indeed, this approach is being replicated by many rare diseases on an individual basis. Perhaps if all the different rare disease groups collaborated and had these discussions at one time, there could be synergistic effects in terms of prior experience, cost effectiveness and time-savings.

\section{Increased financial incentive: making the business case}

The previous examples of cross-sector collaboration all require either significant financial investment and/or labor outlays. Many rare disease patient advocacy organizations lack substantial funding 
resources, staff numbers, or even the experienced individuals needed to coordinate collaborations, which limits the options for collaborating with biopharmaceutical companies to encourage greater investment in rare diseases. However, there is an option that is less labor- or finance-intensive: advocating directly to and within the company to support the development of internal programs in rare diseases and providing disease expertise and information.

The National Brain Tumor Society, for example, has collaborated with two biotechnology companies to help them launch braincancer-specific programs internally. For both companies, there were a series of meetings and presentations by the patient advocacy group in order to educate the company about the following:

- Unmet need

- Current research landscape

- Treatment paradigm

- Market potential/size

One of the companies is now collaborating with two of the National Brain Tumor Society's funded researchers, and the other is funding a pilot program in brain cancer. The companies are leveraging their expertise in specific technology to adapt and optimize it for brain cancer treatment. These are pre-clinical programs, and it is anticipated that the relationships and collaborations between the National Brain Tumor Society and the biotechnology companies will continue throughout the development process. It is exciting to see novel technologies applied to a new area where the companies are taking the additional step of tailoring them to the unique needs of the biology of the disease and the patient population. Each company required a different approach, and all collaborations have to be structured to be sensitive to the needs and expectations of each. The passion and commitment of the patient advocacy groups involved were the key drivers in each case. These highly innovative programs have flourished because of the rare disease patient community. It is expected that continued innovation in identifying opportunities will allow further future successes.

\section{Opportunities in rare disease}

Given the current funding environment for academic and startup researchers, it is interesting to note that there may be potential for a surge in rare disease interest and investment. It may seem counterintuitive, but we can look to the 2008 recession for the rationale. In a lean environment where resources are scarce (i.e., the economy is in recession), we often see a boom in startups, as in post- $2008^{20}$. High unemployment and limited options led some to be more willing to take on risks such as starting their own business. In short, their opportunity cost has lowered. Similarly, with more academic researchers competing for shrinking federal funding resources, taking on the "risk" of investigating a rare disease indication, which traditionally would have been unappealing due to the lack of resources or a clear career path, has become more desirable. As many trained scientists leave academia, this may be an opportunity to draw their attention and expertise to rare diseases through resources like patient advocacy groups which in turn make some funding available. The decrease in traditional opportunities can then be coupled with the lower cost of getting started in rare disease research. For example, because less research has been done in these orphan areas, some of the most basic (and less expensive) research has yet to be performed. Initial genomic sequencing and analysis for mutations, for example, is cheaper and faster than the more advanced work that is the initial starting point in other more common diseases. Rare disease advocates often must be more imaginative and innovative in order to leverage their limited resources, and in this case, brain power (in the form of brilliant researchers) is a resource that the rare disease community can leverage by presenting a strong case for the career and research opportunities available by focusing in an orphan area.

\section{Doing more with less—sharing resources}

An additional approach for small rare disease foundations is to pool their resources, and that could be at the level of organizational staff for fund raising or at the scientific level. For example, one experienced scientific consultant could oversee the science collaborations for multiple distinct organizations dealing with the same or different rare diseases. This not only has cost savings but also the potential to see synergies across projects and research. This may increase the potential for serendipitous discovery that might synergize the overall research goals for multiple diseases. Obviously, there need to be boundaries to respect the intellectual property of groups involved, but the benefits may outweigh the risks.

\section{A coordinated research effort}

From our own experience of working as researchers or facilitators of collaborations between different groups working on rare diseases, we will now describe some of the results of ongoing efforts. The aim is to give the reader some understanding of the breadth of technologies applied and the number of approaches being worked on simultaneously. Recent examples suggest that through collaborative efforts, more progress can be made.

\section{Spinal Muscular Atrophy}

Spinal Muscular Atrophy (SMA) is a childhood-onset, neurodegenerative disorder that is characterized by the loss of motor neurons and affects approximately one in 11,000 people. The disease has a range of clinical presentations, which are categorized into four types $^{21,22}$. Type I, the most severe form that represents approximately $60 \%$ of cases, is diagnosed prior to six months of age, and patients do not gain the ability to sit. In 1995, researchers uncovered the genetic basis of the disorder, which accounts for at least $95 \%$ of cases, mutations in the Survival of Motor Neuron1 (SMN1) gene ${ }^{23}$. In addition to SMN1, humans have a variable number of copies of the SMN2 gene, which differs from SMN1 by a single nucleotide, and leads to a change in the splicing pattern, resulting in a truncated form of the protein that is quickly degraded ${ }^{24,25}$. The severity of SMA is determined by the number of copies of SMN2, with type I patients having fewer copies. This knowledge allowed for the development of animal models ${ }^{26-28}$ and drug discovery assays based on splicing modification and the levels of $\mathrm{SMN}^{29}$. In addition, basic science understanding such as the function of the SMN protein could be probed. Answers to important questions for translational decisions, like where in the body SMN levels must be increased (both in neurons and peripherally) and when treatment is required for response (early intervention is better, but rescue is possible after onset of symptoms) have also been addressed ${ }^{30,31}$. Despite the 
complexity of the SMN protein and the disease pathology, with a clear directive in mind such as to increase levels of SMN by inducing transcription, changing splicing, or preventing protein degradation, the research community has many interesting findings to date which have resulted in five promising drug candidates in clinical trials and at least 11 preclinical programs ${ }^{29}$. Four out of the five clinical candidates are directly targeting SMN expression, either through gene therapy or modulation of SMN2 transcription or splicing with small molecules or an antisense oligonucleotide (ASO) ${ }^{30,32-37}$ (Table 2). The furthest along of these candidates is the ISIS-SMN $_{\mathrm{Rx}}$ ASO, being developed by ISIS Pharmaceuticals and Biogen-IDEC, which is currently in a Phase III trial ${ }^{38}$.

SMA research in academia and in industry has been strongly supported and guided by the SMA Foundation ${ }^{39}$ and CureSMA ${ }^{40}$ (formerly known as Families of SMA Foundation), which both coordinated research efforts, fostered collaborations, enticed biopharma companies, and developed an extensive patient network for clinical trials. Through these foundations, patient involvement in research was critical for genomic studies, understanding the natural history of SMA, development of induced pluripotent stem cells for disease modeling, clinical trials, and identifying biomarkers. Collaborative partnerships between academia, government, pharmaceutical companies, and non-profits accelerated efforts in compound screening on biochemical and cellular assays, animal testing, and other aspects of drug development, have led to the creation of a robust pipeline over a fifteen year period.

\section{Charcot-Marie-Tooth}

CMT affects approximately one in 2500 Americans $^{41}$. Patients usually have muscle weakness, which results in difficulty walking and gripping objects and progresses to foot and hand deformities, decreased reflexes, and bilateral foot drop ${ }^{42}$. In most cases, the cause is genetic but it can also be induced by other factors such as certain chemotherapy drugs. The Peripheral Myelin Protein 22 (PMP22) gene duplication predominantly causes the most common form of CMT called CMT1 $\mathrm{A}^{4,43}$. There is no treatment for any of the CMTs for which symptoms usually present in the first two decades of life ${ }^{44}$.

Despite discovery of the causal gene duplication in 1991, the first high throughput screen (HTS) targeting PMP22 was not published until 21 years later in $2012^{45}$. Thus, CMT1A is one of many rare disorders where fundamental discoveries in academia progress slowly towards the therapeutic development. Still, the pipeline for CMT1A looks quite promising with Pharnext announcing a phase III clinical trial for PXT-3003 (a combination therapy of FDA-approved components baclofen, naltrexone and sorbitol) in 2014-2015 $5^{46,47}$. If the Phase III clinical trial is ultimately successful, this could be the first treatment to market. Still, success is not a given, as success rates for investigational drugs in phase III trials from a recent analysis was $60.1 \%$. The pharmaceutical company Addex announced a preclinical study of ADX71441, a GABA-B receptor (GABA-BR) positive allosteric modulator (PAM) compound ${ }^{49}$. Most recently, researchers at the Max Planck Institute (Germany) announced how Neuregulin-1 might represent a promising approach to therapy ${ }^{50}$. These latter two therapies are likely many years from the clinic.

There are two foundations focused on developing treatments for CMT. The first is the Hereditary Neuropathy Foundation (HNF) ${ }^{51}$. This group has funded a number of model systems to further research, including the development of a high content screen of over 25,000 compounds for CMT1A (PMP22) and CMT1E (point mutation), the establishment of transgenic CMT1A rat models, a CMT2A (MFN2 mutation) mouse model for testing therapeutics, and a CMT2A zebrafish model for screening. HNF also developed a global registry for inherited neuropathies ${ }^{19}$. Recently HNF partnered with Pharnext to raise awareness of CMT1A in preparation for their phase III clinical trial. The Charcot-Marie-Tooth Association ${ }^{52}$ has also raised funds to develop laboratory models and assays at academic partners, perform HTS screening at the National Institutes of Health (NIH) and with pharmaceutical companies (it recently announced a partnerships with Genzyme and Addex). To date the most advanced work has focused on PMP22 for CMT1A. The CMTA has also set up a relationship with a contract research organization to perform drug testing in laboratory models of CMT1A. This foundation also funds work on other CMT forms but this appears to be at an earlier stage than for CMT1A.

The Inherited Neuropathy Consortium Rare Diseases Clinical Research Network (RDCRN) is an NIH collaboration between CMT researchers. Over the past five years, with funding likely in excess of $\$ 5$ million, this network has focused on determining the natural history of CMT through clinical (https://www.rarediseasesnetwork. org/INC/studies/index.htm) projects and may be engaged in the future for testing treatments.

Table 2. Drug candidates in clinical trials for the treatment of SMA.

\begin{tabular}{|c|c|c|c|c|}
\hline $\begin{array}{l}\text { SMA Drug } \\
\text { Candidates }\end{array}$ & Company & Category & Mechanism & Clinical Trials \\
\hline olesoxime & Trophos & Small molecule & Neuroprotectant & Completed \\
\hline RG3039 & Pfizer & Small molecule & $\begin{array}{l}\text { DcpS inhibitor, SMN2 } \\
\text { promoter activity }\end{array}$ & $\begin{array}{l}\text { Completed Phase } \\
\text { la and IB safety }\end{array}$ \\
\hline ISIS-SMN $_{\mathrm{Rx}}$ & $\begin{array}{l}\text { Isis Pharmaceuticals and } \\
\text { Biogen Idec }\end{array}$ & $\begin{array}{l}\text { Antisense oligonucleotide } \\
\text { (ASO) }\end{array}$ & SMN2 Splicing modulator & Beginning Phase III \\
\hline RG7800 & $\begin{array}{l}\text { Roche, PTC Therapeutics, } \\
\text { SMA Foundation }\end{array}$ & Small molecule & SMN2 Splicing modulator & Beginning Phase I \\
\hline chariSMA & $\begin{array}{l}\text { AveXis, Nationwide } \\
\text { Children's Hospital in } \\
\text { Columbus, OH }\end{array}$ & $\begin{array}{l}\text { Intraveneously delivered } \\
\text { AAV9/SMN1 gene transfer } \\
\text { therapy }\end{array}$ & Gene therapy & Phase I \\
\hline
\end{tabular}


At first glance this represents an incredible amount of activity for CMT, but it is worth also considering that there have been considerable failures such as the use of high-dose ascorbic acid for CMT1 $^{53,54}$. The heavy focus on PMP22 is a risk given the heterogeneity of the disorder, and this could be mitigated in some way by more collaboration between researchers and foundations to avoid potential for overlap and also explore new approaches. Screening more compounds against PMP22 is likely not going to lead to more insights, and learning from the data already generated via computational modeling would perhaps be beneficial. CMT research is not unique amongst rare diseases in having trouble translating discoveries in the lab into the clinic. It is clear that millions of dollars can be invested by both foundations and the NIH with no guarantee of a treatment resulting from it. Rare disease patients and foundations need to have realistic expectations of the length of time it takes to go from a HTS to the clinic.

\section{Giant Axonal Neuropathy}

Giant Axonal Neuropathy (GAN) is a recessively inherited condition that results in progressive nerve death ${ }^{55}$, and it has been reviewed previously ${ }^{9,19}$. GAN may be closely related to CharcotMarie-Tooth Type 2 (CMT Type 2) ( $^{56}$, and some pathological factors are also hallmarks of amyotrophic lateral sclerosis (ALS or Lou Gehrig's Disease) $)^{57}$, CMT 2E ${ }^{58}$, Alzheimer's disease, Parkinson's disease, diabetic neuropathy, SMA, as well as other diseases ${ }^{59}$. A parent/patient led foundation, Hannah's Hope Fund (HHF ${ }^{60}$ has raised over $\$ 5$ million to fund the development of a gene therapy ${ }^{61}$.
In addition, they are also funding a postdoc at National Center for Advancing Translational Sciences (NCATS) to develop an assay and screen compounds. This illustrates what can be achieved in a short period of time by promoting collaboration between different academic and government research groups ${ }^{9,19}$ and perhaps represents a model that other groups could emulate.

\section{Sanfilippo syndrome}

Sanfilippo syndrome (mucopolysaccharidosis type III; MPS III) is a devastating neurodegenerative lysosomal storage disorder of childhood. The cause of MPS III is an inherited mutation in one of four enzymes required to catabolize heparan sulfate (HS). The four subtypes of the disease are defined by the enzyme deficiency: MPS III type A (heparan N-sulfatase); MPS III type B $(\alpha-\mathrm{N}$-acetylglucosaminidase); MPS III type $\mathrm{C}$ (heparan sulfate acetyl CoA: $\alpha$-glucosaminide $\mathrm{N}$-acetyltransferase, HGSNAT); and MPS III type D (N-acetylglucosamine 6-sulfatase) ${ }^{62}$. All subtypes of MPS III have similar clinical phenotypes with onset in infancy or early childhood: progressive and severe neurological deterioration, hearing loss, and visceral manifestations ${ }^{62}$. There is currently no cure or effective treatment available for MPS III. There are however many therapies in early development (Table 3), including gene therapies, enzyme replacement, chaperone and substrate reduction therapeutics. With Sanfilippo MPSIII Type A there is currently a large focus on gene therapy evaluating different vectors (adenoassociated virus (AAV) e.g. AAV5, AAV9, AAVrh.10 etc) across many different groups. Less research appears to be focused on types

Table 3. A list of some examples of treatments under development and the research groups involved for Sanfilippo Syndrome. This is by no means exhaustive and we are aware of other efforts, but these are not public knowledge in many cases. (This table is an updated version of that found at https://www.rareconnect.org/en/community/sanfilippo-syndrome/article/ current-sanfilippo-research-programs-in-the-clinical-stage).

\begin{tabular}{|l|l|l|}
\hline $\begin{array}{l}\text { Sanfilippo } \\
\text { Syndrome Type }\end{array}$ & $\begin{array}{l}\text { Treatment } \\
\text { Gene Therapy SAF-301 completed } \\
\text { A }\end{array}$ & Company Group \\
\hline A & Gene therapy & $\begin{array}{l}\text { Lationwide Children's Hospital/ } \\
\text { Abeona Therapeutics }\end{array}$ \\
\hline A & Gene therapy & Esteve \\
\hline A & Enzyme replacement therapy & Shire \\
\hline A & Stem cells & Univ. Manchester \\
\hline A & Substrate reduction therapy Genistein & Univ. Manchester \\
\hline B & Gene therapy ongoing phase I/II & Pasteur Inst. \\
\hline B & Gene therapy & $\begin{array}{l}\text { Nationwide Children's Hospital/ } \\
\text { Abeona Therapeutics }\end{array}$ \\
\hline B & Enzyme replacement therapy & Biomarin/Synageva \\
\hline B & Substrate reduction therapy Genistein & Univ. Manchester \\
\hline C & Chaperone & Univ. Montreal ${ }^{98}$ \\
\hline C & Gene Therapy & Univ. Manchester \\
\hline & Substrate reduction therapy Genistein & Univ. Manchester \\
\hline D & Enzyme replacement therapy & LaBioMed/Phoenix Nest ${ }^{99}$ \\
\hline
\end{tabular}


C, D (Table 3). Due to the limited pool of funding for this disorder, enhanced collaboration may prevent unnecessary redundancies and broaden the impact of the ongoing research efforts as well as make the investments go further.

\section{A broad impact}

The primary goal of rare disease research is to find a cure or treatment strategy for the disorder in question, but rare diseases offer a glimpse into the roles of genes and proteins in human disease pathogenesis in general. The therapeutics developed to treat rare disorders may also be useful in treating additional disorders whether rare or common. This has proven to be true for drugs developed for rare cancer indications. For example, imatinib $\left(\right.$ Gleevec $\left.^{\circledR}\right)$ was originally approved for Philadelphia chromosome positive CML, which contains the oncogenic BCR-ABL tyrosine kinase mutation ${ }^{63,64}$. Imatinib is a well-absorbed drug with activity against multiple tyrosine kinases beyond BCR-ABL, including c-KIT and PDGFRA ${ }^{65,66}$. Due to these other activities, imatinib is effective at treating gastrointestinal stromal tumors (GIST) which are dependent on c-KIT, many other cancers, and steroid refractory Graft-versus-Host disease which requires PDGFRA activity ${ }^{67}$. Thus drugs developed for one rare disease can serve broader roles based on related biological mechanisms.

\section{Software for collaborations}

There appears to be increased interest in scientific collaborations on a large scale and developing a software to facilitate this ${ }^{68}$. For rare diseases, collaborations even on a small scale could have real impact. Instead of scientists hoarding their data, we could remove unnecessary duplication and speed development.

\section{Collaborative Drug Discovery (CDD) vault}

Research collaborations are seen as important for drug discovery to speed up biomedical research, reduce costs, and prevent unnecessary repetition of experiments ${ }^{69}$. There are however considerable intellectual property (IP) concerns to be overcome when sharing data $^{70,71}$. Increasingly, pharmaceutical companies are involved in multi-organization collaborations and public-private partnerships (PPP). To address these issues, Collaborative Drug Discovery, Inc. (CDD) created a software which enables researchers to have their own private vault for storing chemistry and biology data, which can be securely shared and mined while maintaining IP status ${ }^{72}$. CDD itself has found a niche in hosting large-scale collaborations such as More Medicines for Tuberculosis (MM4TB), Bill and Melinda Gates Foundation (BMGF) TB Accelerator ${ }^{73}$, and the NIH Blueprint for Neuroscience Research (BPN). In addition, rare disease research organizations, such as the Myelin Repair Foundation (MPF) and Jonah's Just Begun, have used CDD to manage ongoing drug discovery efforts. CDD has a trove of public information, which provides datasets that can be useful for rare disease researchers. These include FDA approved drugs and compounds that have been identified by in vitro screening for repurposing ${ }^{74}$, and the National Center for Advancing Translational Sciences (NCATS) molecules for repurposing ${ }^{75}$. CDD has recently added the NIH's Molecular Libraries Probe Production Centers Network (MLPCN) probe compounds alongside the scoring of these molecules by an experienced medicinal chemist ${ }^{76}$. Comparison of these public datasets with private data may lead to novel drug repositioning ideas, which may in turn mean an accelerated path towards new treatments $\mathrm{s}^{74,77,78}$. Many academic screening centers are focused on repurposing current FDA approved compounds ${ }^{79}$, so the missing piece is developing phenotypic or target based screens for more rare diseases.

\section{Open Drug Discovery Teams (ODDT)}

Beyond the desktop, we must seriously consider how mobile devices could be used to share data and foster collaborations in rare diseases. A mobile app called Open Drug Discovery Teams $(\text { ODDT })^{80,81}$ was created to collect Twitter feeds on multiple scientific hashtags (e.g., rare diseases like \#huntingtons, and \#sanfilipposyndrome, \#gaucher, \#huntersyndrome \#fabry, \#Tay-Sachs, \#NGLY1, \#hurlersyndrome, \#pompedisease, \#krabbe, \#fmdaware, \#niemannpick and \#Batten). Collecting tweets and information from the web creates an open database for these diseases. The architecture of ODDT has been described recently ${ }^{82}$, and the use and function of the app have also been discussed ${ }^{80}$. The app is also small molecule aware so it can be used to share structures and activity data. The limited funding available for rare disease drug discovery and development suggests why we should be looking at alternative, lower cost approaches. ODDT could even become a useful assistant to scientists, small rare disease foundations, and advocates to help find collaborators or groups to fund. ODDT is ultimately a simple tool that uses Twitter for serious science applications that could be expanded in several directions to help the rare disease community. For example, besides collaboration towards one rare disease treatment, there is also opportunity for rare disease researchers to work together to compare HTS drug discovery data. Can rare disease groups learn from one another? Could hits found for related rare diseases have additional applications, or might safety and toxicity issues be determined earlier if the data were compared sooner?

\section{What is still needed}

Dissemination of information to patients, physicians and advocates that connects genetics to pharmacology

How can treatment options be identified and/or created in a patient relevant time frame? The most obvious way is to identify an approved medicine that could be repurposed, or if warranted, used off label. Another option is to discover a medicine specific for that disease. Currently only few medicines are discovered each year for rare diseases. A recent analysis showed only 46 first in class medicines approved for rare diseases in a 14 year period ${ }^{3}$. With almost 7000 rare diseases, it is impossible to discover medicines for all of these using current research practices. Clearly, the number of identified human rare disease genes significantly outstrips the number of global research laboratories available to investigate a given disorder. The current productivity of drug discovery will never fill this need. Therefore, the development of a strategic toolbox and preclinical research pathway for inherited rare diseases has been proposed ${ }^{83}$.

The unfortunate reality of drug discovery as it is currently practiced is it is a long and costly process. Increased success in rare disease 
drug discovery will require better diagnostics, an understanding of disease that provides good translational biomarkers, and clearer clinical development programs. The mechanisms underlying rare diseases are not well understood, patients are hard to identify and diagnose, and no regulatory precedent for the disease may exist, all of which makes designing and conducting drug development programs very difficult. There has been a dramatic increase in research and development spending without the corresponding increases in new medicines. The current trend is to spend more to increase knowledge, however this has not increased the clinical success rate. The low productivity is unacceptable for rare disease drug discovery. Funds need to be used more efficiently. The new knowledge needs to be used more effectively to identify treatment options. Solutions that provide for more treatment options in addition to new medicines are needed. Some hope in rare diseases is provided by understanding the genetic cause to the disease. As noted above, greater than $80 \%$ of rare diseases are due to a genetic defect. This understanding can focus research efforts and inform potential medical treatments. However, knowing the identity of a casual gene does not readily lead to a medicine that will cure the disease. Opportunities exist to use the genetic information to provide treatment options, in addition to informing drug discovery research.

What are the options if there is not the time or funding available to discover and develop new medicines? One potential option is to identify molecules approved for human use including pharmaceuticals, nutraceuticals and herbal products that can be safely given to patients. While this seems obvious, there is a huge barrier to the dissemination of information between researchers and patients, physicians and advocates to develop a treatment plan based on all the available information. For rare disease researchers, a comprehensive data management system that consolidated the underlying genetic and protein causes of these disparate rare diseases would be hugely useful. Bringing these data together in a comprehensive database with information that reaches beyond just the underlying gene to other biological relevant information such as pathway analysis will be critical to researchers performing drug discovery on these disparate diseases. In parallel, the patient of a child with a rare or ultra-rare disease has few options in the USA as there is currently no single entity that covers all rare disease research and clinical translational work. Ideally, a comprehensive database would be presented to patients and advocates in a factual manner that is easy to understand, difficult to misinterpret, and could lead to connections with scientific and medical experts.

The assimilation and dissemination of knowledge from the many scientific areas important to medicine, including genetics, biology, chemistry and pharmacology, is challenging even for experts. Tools that provide this information to patients, physicians and advocates will be of value to help provide insights into new treatment options and to identify new opportunities. For example, providing information on approved medicines or remedies in which the pharmacology could be related to a specific physiological system and/or gene may identify new treatment options and/or new research directions. One approach to address this need is with an in silico database, in which the knowledge is easily used by both professionals and nonprofessionals. We envision that the identification of a new gene and the corresponding biology may provide insights into pharmacology that may be addressed with approved medicines. This knowledge could be of use to identify compounds for testing in animal and cellular studies. There is also the possibility of off label use in the patients with the proper monitoring, if no other treatment options are available.

It can be a challenge to match pharmacology with biology and genetics, especially for non-experts. Even domain experts in genetics and biology, may not know the corresponding pharmacology and vice versa. A database or collaborative network that specifically provides this information and access to experts will be of value to patients with rare diseases. For example, commercially available databases already exist that relate a gene to biological pathways with known pharmacology ${ }^{84}$ and could help identify treatment options amongst FDA-approved drugs, nutraceuticals or other compounds.

The details of hereditary angioedema (HAE) provide a nice example of how the identification of the mutated genes led investigators to identify the biological systems involved, which in turn provided clues to potential pharmacological intervention and approved therapeutics ${ }^{85}$. HAE is a rare genetic disorder that leads to episodes of extreme swelling caused by mutations to $\mathrm{C} 1$-esterase-inhibitor (C1-INH), a protease inhibitor that functions in the complement cascade in the immune system ${ }^{86}$. HAE is characterized by low levels of C1-INH activity and low levels of C4 in the classical complement pathway ${ }^{87}$. C1-INH regulates the activation of complement and intrinsic coagulation (contact system pathway), and is a major endogenous inhibitor of plasma kallikrein. The kallikrein-kinin system is a complex proteolytic cascade involved in the initiation of both the inflammatory and coagulation pathways. One critical aspect of this is the conversion of High Molecular Weight (HMW) kininogen to bradykinin by the protease plasma kallikrein. In HAE, normal regulation of plasma kallikrein activity and the classical complement cascade is not present. During attacks, unregulated activity of plasma kallikrein results in excessive bradykinin generation. Bradykinin is a vasodilator which is thought to be responsible for the characteristic HAE symptoms of localized swelling, inflammation, and pain ${ }^{88}$. Two treatments for acute episodic attacks of HAE were developed once the causative gene was uncovered and required an in-depth understanding of the biology. Ecallantide binds to plasma kallikrein inhibiting the conversion of HMW kininogen to bradykinin ${ }^{89}$. Icatibant is a competitive antagonist selective for the bradykinin B2 receptor ${ }^{90-92}$. Thus, this provides a clear example of how genetics can be connected to known pharmacology.

St. Jude Children's Research Hospital, which from humble beginnings has transformed many cancers of children into treatable diseases through combined basic and translational research while at the same time becoming a world class center of excellence, offers a glimmering example or model for the rare disease community. Perhaps a dedicated rare disease institute to help facilitate and organize collaboration for translational research could be valuable. The development of such a center would need coordination between foundations, philanthropists, researchers, and government to ensure that it could become a reality. 
It is our opinion that we need to centralize many of the rare disease efforts and translate findings to other rare diseases where there may not be current organizations driving the research. These efforts could include the development of databases of transcriptional profiles for thousands of compounds which many pharmaceutical companies have access to. Computational advances could be used in so many areas that would help rare disease research. This might include improving the prediction of small molecule-RNA/protein interactions, generalizing ADME-toxicology for oligonucleotides, or possibly identifying a druggable pathway that allows the persistence of higher levels of mutated and mis-folded protein. These may be just starting points for additional investments. With so many in silico cheminformatic and bioinformatic methods ${ }^{93,94}$, bringing them together via data integration platforms like those for systems biology, could help areas of research such as chaperonin identification ${ }^{74,95}$. Unfortunately, there is currently no definitive database for collaboration and education that disseminates available knowledge to rare disease stake holders (patients, physicians, advocates) in a usable/ interpretable form. Such a database may provide insights into additional treatment options in a time frame relevant to patients.

An institute for rare diseases, which could be informatics driven, to centralize and direct the various ongoing academic collaborations funded by the rare disease groups would be a huge advance for optimal collaboration. Such an effort could use the various existing databases to mine for compounds as potential treatments for rare diseases. A recent effort to collate 456 FDA compounds approved for use in the pediatric population may be a starting point for repurposing these compounds for rare diseases computationally ${ }^{96}$.
An institute would partner with a center with HTS screening resources and would leverage existing infrastructure and researchers across many other institutes. Rare disease patient groups would be targeted to provide foundational funding and access to their complete researcher and patient networks. Pharmaceutical companies would be involved to provide access to compounds and databases for mining. In addition, advice from a scientific advisory board of experienced drug developers would be critical. The institute would share IP with the groups involved. The goal would be the creation of a world class center for rare diseases, becoming a magnet for global rare disease researchers, clinicians, patients, and companies, and it would be self-funding. The ultimate measure of its success would be how many treatments for rare diseases would be approved.

\section{A hopeful future}

The features of rare diseases that lead to their unique challenges can also become advantages for finding new therapeutics. Once united, a well-defined patient population, a defined genetic etiology, and a dedicated advocacy foundation can catalyze drug discovery. Collaboration between all of the key entities (Figure 1), including academic institutions, government, biopharmaceutical companies, advocacy organizations, and non-profits is critical for moving rare disease drug discovery efforts forward. In addition, computational approaches can help foster the collaborations, add efficiency, build on previous efforts, and ultimately drive research in new directions. Individual rare disease researchers may also benefit from working together, perhaps through a centralized institute, to share resources towards the ambitious goal of finding treatments for the large unmet need.

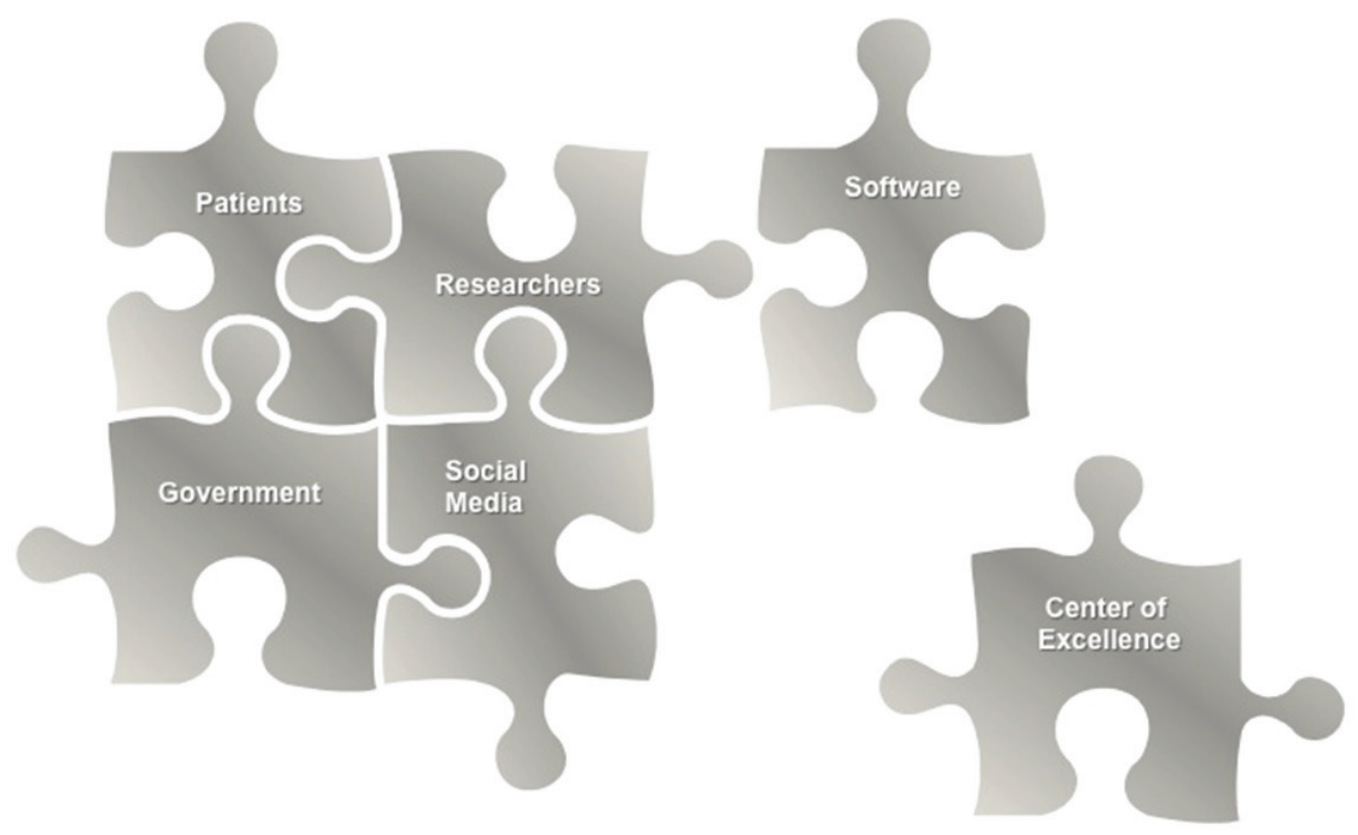

Figure 1. An illustration of the pieces of the rare disease jigsaw that could be brought together for developing treatments more efficiently. 


\section{Author contributions}

N.K.L. and S.E. came up with the general idea for the Opinion Article. All authors contributed to the collaborative writing of this project.

\section{Competing interests}

S.E. works for Collaborations in Chemistry, and consults for Collaborative Drug Discovery Inc. as well as rare disease groups including the Hereditary Neuropathy Foundation, Hannah's Hope Fund and Phoenix Nest. N.K.L. works for Collaborative Drug Discovery Inc. M.R. works for National Brain Tumor Society. D.C.S. works for the Institute for Rare \& Neglected Diseases Drug Discovery.
Grant information

The author(s) declared that no grants were involved in supporting this work.

\section{Acknowledgments}

The authors would like to acknowledge Jill Wood and Raquel Marques (Jonah's Just Begun-Foundation to Cure Sanfilippo Inc.) for assistance compiling Table 3. Lori Sames (Hannah's Hope Fund) and Allison Moore (Hereditary Neuropathy Foundation) are also acknowledged for their support and information that enabled the summaries of GAN and CMT, respectively. Our colleagues at CDD are acknowledged for their efforts in developing the CDD Vault. Dr. Alex Clark is kindly acknowledged for co-developing the ODDT mobile app.
1. Melnikova I: Rare diseases and orphan drugs. Nat Rev Drug Discov. 2012; 11(4): 267-8.

PubMed Abstract | Publisher Full Text

2. Field MJ, Boat TF: Rare Diseases and Orphan Products: Accelerating Research and Development. Washington DC: The National Academics Press. 2011. Reference Source

3. Swinney DC, Xia S: The discovery of medicines for rare diseases. Future Med Chem. 2014; 6(9): 987-1002.

PubMed Abstract | Publisher Full Text

4. DiVincenzo C, Elzinga CD, Medeiros AC, et al:: The allelic spectrum of CharcotMarie-Tooth disease in over 17,000 individuals with neuropathy. Mol Genet Genomic Med. 2014. In press. Publisher Full Text

5. Grabowski $P$, Briest $F$, Baum RP, et al.: Vandetanib therapy in medullary thyroid cancer. Drugs Today (Barc). 2012; 48(11): 723-33. PubMed Abstract

6. Ogawa S, Takita J, Sanada M, et al:: Oncogenic mutations of ALK in neuroblastoma. Cancer Sci. 2011; 102(2): 302-8

PubMed Abstract | Publisher Full Text

7. Paul SM, Mytelka DS, Dunwiddie CT, et al.: How to improve R\&D productivity: the pharmaceutical industry's grand challenge. Nat Rev Drug Discov. 2010; 9(3): 203-14.

PubMed Abstract | Publisher Full Text

8. Munos B: Lessons from 60 years of pharmaceutical innovation. Nat Rev Drug Discov. 2009; 8(12): 959-68.

PubMed Abstract | Publisher Full Text

9. Wood J, Sames L, Moore A, et al.: Multifaceted roles of ultra-rare and rare disease patients/parents in drug discovery. Drug Discov Today. 2013; 18(21-22): 1043-1051

PubMed Abstract | Publisher Full Text

10. Miyamoto BE, Kakkis ED: The potential investment impact of improved access to accelerated approval on the development of treatments for low prevalence rare diseases. Orphanet J Rare Dis. 2011; 6: 49. PubMed Abstract | Publisher Full Text | Free Full Text

11. Beaulieu CL, Samuels ME, Ekins S, et al.: A generalizable pre-clinical research approach for orphan disease therapy. Orphanet J Rare Dis. 2012; 7: 39. PubMed Abstract | Publisher Full Text | Free Full Text

12. Terry N: Health privacy is difficult but not impossible in a post-HIPAA datadriven world. Chest. 2014; 146(3): 835-40. PubMed Abstract | Publisher Full Text

13. Perkins JA, Coltrera MD: Relational databases for rare disease study: application to vascular anomalies. Arch Otolaryngol Head Neck Surg. 2008, 134(1): 62-6. PubMed Abstract | Publisher Full Text

14. Anon. Sermo. Reference Source

15. Anon. Doximity. Reference Source

16. Might M, Wilsey M: The shifting model in clinical diagnostics: how nextgeneration sequencing and families are altering the way rare diseases are discovered, studied, and treated. Genet Med. 2014; 16(10): 736-7. PubMed Abstract | Publisher Full Text
17. Mnookin S: One of a kind, in The New Yorker. 2014. Reference Source

18. Rhee M, Mui P, Cadogan C, et al:: The role of brain tumor advocacy groups. Curr Neurol Neurosci Rep. 2014; 14(4): 442. PubMed Abstract | Publisher Full Text

19. Sames L, Moore A, Arnold R, et al:: Recommendations to enable drug development for inherited neuropathies: Charcot-Marie-Tooth and Giant Axonal Neuropathy. F1000Res. 2014; 3: 83 PubMed Abstract | Publisher Full Text | Free Full Text

20. Foundation EMK: The Kauffman Index of Entrepreneurial Activity: 1996-2013. 2014. Reference Source

21. Pearn J: Autosomal dominant spinal muscular atrophy: a clinical and genetic study. J Neurol Sci. 1978; 38(2): 263-75. PubMed Abstract | Publisher Full Text

22. Zerres K, Rudnik-Schoneborn S: Natural history in proximal spinal muscular atrophy. Clinical analysis of $\mathbf{4 4 5}$ patients and suggestions for a modification of existing classifications. Arch Neurol. 1995; 52(5): 518-23. PubMed Abstract | Publisher Full Text

23. Lefebvre $\mathrm{S}$, Bürglen L, Reboullet $\mathrm{S}$, et al.: Identification and characterization of a spinal muscular atrophy-determining gene. Cell. 1995; 80(1): 155-65. PubMed Abstract | Publisher Full Text

24. Lefebvre $\mathrm{S}$, Burlet $\mathrm{P}$, Liu $\mathrm{Q}$, et al:: Correlation between severity and SMN protein level in spinal muscular atrophy. Nat Genet. 1997; 16(3): 265-9. PubMed Abstract | Publisher Full Text

25. Lorson CL, Hahnen E, Androphy EJ: A single nucleotide in the SMN gene regulates splicing and is responsible for spinal muscular atrophy. Proc Natt Acad Sci U S A. 1999; 96(11): 6307-11. PubMed Abstract | Publisher Full Text | Free Full Text

26. Edens BM, Ajroud-Driss S, Ma L, et al:: Molecular mechanisms and animal models of spinal muscular atrophy. Biochim Biophys Acta. 2014. PubMed Abstract | Publisher Full Text

27. Monani UR, Coovert DD, Burghes AH: Animal models of spinal muscular atrophy. Hum Mol Genet. 2000; 9(16): 2451-7. PubMed Abstract | Publisher Full Text

28. Schmid A, DiDonato CJ: Animal models of spinal muscular atrophy. J Child Neurol. 2007; 22(8): 1004-12.

PubMed Abstract | Publisher Full Text

29. Cherry JJ, Kobayashi DT, Lynes MM, et al:: Assays for the identification and prioritization of drug candidates for spinal muscular atrophy. Assay Drug Dev Technol. 2014; 12(6): 315-41.

PubMed Abstract | Publisher Full Text | Free Full Text

30. Hua Y, Sahashi K, Rigo F, et al.: Peripheral SMN restoration is essential for longterm rescue of a severe spinal muscular atrophy mouse model. Nature. 2011; 478(7367): 123-6. PubMed Abstract | Publisher Full Text | Free Full Text

31. Lutz CM, Kariya S, Patruni S, et al.: Postsymptomatic restoration of SMN rescues the disease phenotype in a mouse model of severe spinal muscular atrophy. J Clin Invest. 2011; 121(8): 3029-41. PubMed Abstract | Publisher Full Text | Free Full Text

32. Naryshkin NA, Weetall M, Dakka A, et al.: Motor neuron disease. SMN2 splicing modifiers improve motor function and longevity in mice with spinal muscular 
atrophy. Science. 2014; 345(6197): 688-93. PubMed Abstract | Publisher Full Text

33. Passini MA, Bu J, Richards AM, et al:: Antisense oligonucleotides delivered to the mouse CNS ameliorate symptoms of severe spinal muscular atrophy. Sci Transl Med. 2011; 3(72): 72ra18.

PubMed Abstract | Publisher Full Text | Free Full Text

34. Gogliotti RG, Cardona H, Singh J, et al.: The DcpS inhibitor RG3039 improves survival, function and motor unit pathologies in two SMA mouse models. Hum Mol Genet. 2013; 22(20): 4084-101.

PubMed Abstract | Publisher Full Text | Free Full Text

35. Van Meerbeke JP, Gibbs RM, Plasterer HL, et al:: The DcpS inhibitor RG3039 improves motor function in SMA mice. Hum Mol Genet. 2013; 22(20): 4074-83. PubMed Abstract | Publisher Full Text | Free Full Text

36. Benkhelifa-Ziyyat S, Besse A, Roda M, et al:: Intramuscular ScAAV9-SMN injection mediates widespread gene delivery to the spinal cord and decreases disease severity in SMA mice. Mol Ther. 2013; 21(2): 282-90. PubMed Abstract | Publisher Full Text | Free Full Text

37. Passini MA, Bu J, Richards AM, et al.: Translational fidelity of intrathecal delivery of self-complementary AAV9-survival motor neuron 1 for spinal muscular atrophy. Hum Gene Ther. 2014; 25(7): 619-30.

PubMed Abstract | Publisher Full Text

38. Garde D: Isis gears up for Phase III with Biogen-partnered antisense drug 2014.

Reference Source

39. Anon. SMA Foundation.

Reference Source

40. Anon. CuresmA.

Reference Source

41. Miller LJ, Saporta AS, Sottile SL, et al.: Strategy for genetic testing in CharcotMarie-disease. Acta Myol. 2011; 30(2): 109-16. PubMed Abstract | Free Full Text

42. Rangaraju S, Verrier JD, Madorsky I, et al.: Rapamycin activates autophagy and improves myelination in explant cultures from neuropathic mice. $J$ Neurosci. 2010; 30(34): 11388-97.

PubMed Abstract | Publisher Full Text | Free Full Text

43. Naef R, Suter U: Many facets of the peripheral myelin protein PMP22 in myelination and disease. Micros Res Tech. 1998; 41(5): 359-371. PubMed Abstract

44. Kaya F, Belin S, Bourgeois P, et al:: Ascorbic acid inhibits PMP22 expression by reducing cAMP levels. Neuromuscul Disord. 2007; 17(3): 248-53. PubMed Abstract | Publisher Full Text

45. Jang SW, Lopez-Anido C, MacArthur R, et al:: Identification of drug modulators targeting gene-dosage disease CMT1A. ACS Chem Biol. 2012; 7(7): 1205-13. PubMed Abstract | Publisher Full Text | Free Full Text

46. Ainsworth C: Networking for new drugs. Nat Med. 2011; 17(10): 1166-8. PubMed Abstract | Publisher Full Text

47. Attarian S, et al:: A phase II randomized, placebo-controlled multicenter clinical trial of three doses of PXT3003 in 80 adult patients with CMT1A treated for 1 year. J Peripher Nerv Syst. 2013; 8: 197-198.

48. Hay M, Thomas DW, Craighead JL, et al.: Clinical development success rates for investigational drugs. Nat Biotechnol. 2014; 32(1): 40-51.

PubMed Abstract | Publisher Full Text

49. Anon. Addex press release. 2014. Reference Source

50. Fledrich R, Stassart RM, Klink A, et al:: Soluble neuregulin-1 modulates disease pathogenesis in rodent models of Charcot-Marie-Tooth disease 1A. Nat Med. 2014; 20(9): 1055-61.

PubMed Abstract | Publisher Full Text

51. Anon. Hereditary Neuropathy Foundation.

Reference Source

52. Anon. Charcot-Marie-Tooth Association. Reference Source

53. Lewis RA, McDermott MP, Herrmann DN, et al:: High-dosage ascorbic acid treatment in Charcot-Marie-Tooth disease type 1A: results of a randomized, double-masked, controlled trial. JAMA Neurol. 2013; 70(8): 981-7. PubMed Abstract | Publisher Full Text | Free Full Text

54. Verhamme $\mathrm{C}$, de Haan RJ, Vermeulen M, et al.: Oral high dose ascorbic acid treatment for one year in young CMT1A patients: a randomised, double-blind, placebo-controlled phase II trial. BMC Med. 2009; 7: 70. PubMed Abstract | Publisher Full Text | Free Full Text

55. Yang Y, Allen E, Ding J, et al.: Giant axonal neuropathy. Cell Mol Life Sci. 2007; 64(5): 601-9.

PubMed Abstract | Publisher Full Text

56. Yiu EM, Ryan MM: Genetic axonal neuropathies and neuronopathies of prenatal and infantile onset. J Peripher Nerv Syst. 2012; 17(3): 285-300. PubMed Abstract | Publisher Full Text

57. Bomont $\mathrm{P}, \mathrm{C}$ Cavalier $\mathrm{L}$, Blondeau $\mathrm{F}$, et al:: The gene encoding gigaxonin, a new member of the cytoskeletal BTB/kelch repeat family, is mutated in giant axonal neuropathy. Nat Genet. 2000; 26(3): 370-4. PubMed Abstract | Publisher Full Text

58. Fabrizi GM, Cavallaro T, Angiari C, et al.: Charcot-Marie-Tooth disease type 2E, a disorder of the cytoskeleton. Brain. 2007; 130(Pt 2): 394-403. PubMed Abstract | Publisher Full Text
59. Mahammad S, Murthy SN, Didonna A, et al.: Giant axonal neuropathy-associated gigaxonin mutations impair intermediate filament protein degradation. $J$ Clin Invest. 2013; 123(5): 1964-75.

PubMed Abstract | Publisher Full Text | Free Full Text

60. Anon. Hannah's Hope Fund.

Reference Source

61. Vandendriessche $T$, Thorrez L, Acosta-Sanchez A, et al:: Efficacy and safety of adeno-associated viral vectors based on serotype 8 and 9 vs. lentiviral vectors for hemophilia B gene therapy. J Thromb Haemost. 2007; 5(1): 16-24. PubMed Abstract | Publisher Full Text

62. Valstar MJ, Ruijter GJ, van Diggelen OP, et al:: Sanfilippo syndrome: a minireview. J Inherit Metab Dis. 2008; 31(2): 240-52.

PubMed Abstract | Publisher Full Text

63. Druker BJ, Talpaz M, Resta DJ, et al:: Efficacy and safety of a specific inhibitor of the BCR-ABL tyrosine kinase in chronic myeloid leukemia. $N$ Engl J Med. 2001; 344(14): 1031-7.

PubMed Abstract | Publisher Full Text

64. Druker BJ, Tamura S, Buchdunger E, et al.: Effects of a selective inhibitor of the Abl tyrosine kinase on the growth of Bcr-Abl positive cells. Nat Med. 1996; 2(5): 561-6.

PubMed Abstract | Publisher Full Text

65. Peng B, Dutreix C, Mehring G, et al.: Absolute bioavailability of imatinib (Glivec) orally versus intravenous infusion. J Clin Pharmacol. 2004; 44(2): 158-62. PubMed Abstract | Publisher Full Text

66. Buchdunger $\mathrm{E}$, Cioffi CL, Law N, et al:: Abl protein-tyrosine kinase inhibitor STI571 inhibits in vitro signal transduction mediated by c-kit and plateletderived growth factor receptors. J Pharmacol Exp Ther. 2000; 295(1): 139-45. PubMed Abstract

67. Iqbal N, Iqbal N: Imatinib: a breakthrough of targeted therapy in cancer. Chemother Res Pract. 2014; 2014: 357027.

PubMed Abstract | Publisher Full Text | Free Full Text

68. Omberg L, Ellrott K, Yuan $\mathrm{Y}$, et al.: Enabling transparent and collaborative computational analysis of 12 tumor types within The Cancer Genome Atlas. Nat Genet. 2013; 45(10): 1121-6.

PubMed Abstract | Publisher Full Text | Free Full Text

69. Ekins S, Hupcey MAZ, Williams AJ: Collaborative computational technologies for biomedical research. Hoboken, NJ: Wiley. 2011.

Publisher Full Text

70. Ekins S, Hohman M, Bunin BA: Pioneering use of the cloud for development of the collaborative drug discovery (cdd) database in Collaborative Computational Technologies for Biomedical Research. S. Ekins, M.A.Z. Hupcey, and A.J. Williams, Editors. Wiley and Sons: Hoboken. 2011.

71. Bunin BA, Ekins S: Alternative business models for drug discovery. Drug Disc Today. 2011; 16(15-16): 643-645. PubMed Abstract | Publisher Full Tex

72. Hohman M, Gregory K, Chibale K, et al.: Novel web-based tools combining chemistry informatics, biology and social networks for drug discovery. Drug Disc Today. 2009; 14(5-6): 261-270. PubMed Abstract | Publisher Full Text

73. Ekins S, Bunin BA: The Collaborative Drug Discovery (CDD) database. Methods Mol Biol. 2013: 993: 139-54.

PubMed Abstract | Publisher Full Text

74. Ekins S, Williams AJ, Krasowski MD, et al:: In silico repositioning of approved drugs for rare and neglected diseases. Drug Disc Today. 2011; 16(7-8): 298-310. PubMed Abstract | Publisher Full Text

75. Southan C, Williams AJ, Ekins S: Challenges and recommendations for obtaining chemical structures of industry-provided repurposing candidates. Drug Disc Today. 2013; 18(1-2): 58-70. PubMed Abstract | Publisher Full Text

76. Litterman NK, Lipinski CA, Bunin BA, et al:: Computational Prediction and Validation of an Expert's Evaluation of Chemical Probes. Submitted, 2014. Publisher Full Text

77. Xu K, Cote TR: Database identifies FDA-approved drugs with potential to be repurposed for treatment of orphan diseases. Brief Bioinform. 2011; 12(4): $341-5$.

PubMed Abstract | Publisher Full Text

78. Dudley JT, Sirota M, Shenoy M, et al.: Computational repositioning of the anticonvulsant topiramate for inflammatory bowel disease. Sci Transl Med. 2011; 3(96): 96ra76.

PubMed Abstract | Publisher Full Text | Free Full Text

79. Bhinder B, Djaballah H: Drug discovery and repurposing at Memorial Sloan Kettering Cancer Center: chemical biology drives translational medicine. ACS Chem Biol. 2014; 9(7): 1394-7.

PubMed Abstract | Publisher Full Text

80. Ekins S, Clark AM, Williams AJ: Open Drug Discovery Teams: A Chemistry Mobile App for Collaboration. Mol Inform. 2012; 31(8): 585-597. PubMed Abstract | Publisher Full Text | Free Full Text

81. Ekins S, Clark AM: Open Drug Discovery Teams. 2012. Reference Source

82. Ekins S, Clark AM, Swamidass SJ, et al:: Bigger data, collaborative tools and the future of predictive drug discovery. $J$ Comput Aided Mol Des. 2014; 28(10): 997-1008.

PubMed Abstract | Publisher Full Text

83. Beaulieu CL, Samuels ME, Ekins S, et al.: A generalizable pre-clinical research 
approach for orphan disease therapy. Orphanet J Rare Dis. 2012; 7: 39 PubMed Abstract | Publisher Full Text | Free Full Text

84. Ekins S, Nikolsky Y, Bugrim A, et al:: Pathway mapping tools for analysis of high content data. Methods Mol Biol. 2007; 356: 319-50.

PubMed Abstract | Publisher Full Text

85. Hemperly SE, Agarwal NS, Xu YY, et al:: Recent advances in the management of hereditary angioedema. J Am Osteopath Assoc. 2013; 113(7): 546-55. PubMed Abstract | Publisher Full Text

86. Cicardi M, Igarashi T, Kim MS, et al.: Restriction fragment length polymorphism of the $\mathbf{C} 1$ inhibitor gene in hereditary angioneurotic edema. J Clin Invest. 1987; 80(6): 1640-3.

PubMed Abstract | Publisher Full Text | Free Full Text

87. Kaplan AP, Joseph K: Pathogenic mechanisms of bradykinin mediated diseases: dysregulation of an innate inflammatory pathway. Adv Immunol. 2014; 121: 41-89.

PubMed Abstract | Publisher Full Text

88. Altman KA, Naimi DR: Hereditary angioedema: a brief review of new developments. Curr Med Res Opin. 2014; 30(5): 923-30. PubMed Abstract | Publisher Full Tex

89. Lehmann A: Ecallantide (Dyax/Genzyme). Curr Opin Investig Drugs. 2006; 7(3): 282-90.

PubMed Abstract

90. http://www.accessdata.fda.gov/scripts/cder/drugsatfda/

91. Hock FJ, Wirth K, Albus U, et al:: Hoe $\mathbf{1 4 0}$ a new potent and long acting bradykinin-antagonist: in vitro studies. Br J Pharmacol. 1991; 102(3): 769-73. PubMed Abstract | Publisher Full Text | Free Full Text
92. Wirth K, Hock FJ, Albus U, et al:: Hoe 140 a new potent and long acting bradykinin-antagonist: in vivo studies. Br J Pharmacol. 1991; 102(3): 774-7. PubMed Abstract | Publisher Full Text | Free Full Text

93. Ekins S, Mestres J, Testa B: In silico pharmacology for drug discovery: methods for virtual ligand screening and profiling. Br J Pharmacol. 2007; 152: 9-20. PubMed Abstract | Publisher Full Text | Free Full Text

94. Ekins S, Mestres J, Testa B: In silico pharmacology for drug discovery: applications to targets and beyond. Br J Pharmacol. 2007; 152(1): 21-37. PubMed Abstract | Publisher Full Text | Free Full Text

95. Ekins S, Williams AJ: Finding promiscuous old drugs for new uses. Pharm Res. 2011; 28(8): 1786-1791.

PubMed Abstract | Publisher Full Text

96. Blatt J, Farag S, Corey SJ, et al.: Expanding the scope of drug repurposing in pediatrics: The Children's Pharmacy Collaborative ${ }^{\mathrm{TM}}$. Drug Discov Today. 2014. PubMed Abstract | Publisher Full Text

97. Murrey DA, Naughton BJ, Duncan FJ, et al:: Feasibility and safety of systemic rAAV9-hNAGLU delivery for treating mucopolysaccharidosis IIIB: toxicology, biodistribution, and immunological assessments in primates. Hum Gene The Clin Dev. 2014; 25(2): 72-84

PubMed Abstract | Publisher Full Text | Free Full Text

98. Feldhammer M, Durand S, Pshezhetsky AV: Protein misfolding as an underlying molecular defect in mucopolysaccharidosis III type C. PLoS One. 2009; 4(10): e7434.

PubMed Abstract | Publisher Full Text | Free Full Text

99. Anon. 1R41NS089061-01.

Reference Source 


\title{
Open Peer Review
}

\section{Current Peer Review Status:}

\author{
Version 1
}

Reviewer Report 28 January 2015

https://doi.org/10.5256/f1000research.5946.r7513

(C) 2015 Groft S. This is an open access peer review report distributed under the terms of the Creative Commons Attribution License, which permits unrestricted use, distribution, and reproduction in any medium, provided the original work is properly cited.

\section{Stephen Groft}

Office of Rare Diseases Research, National Institutes of Health, Bethesda, MD, USA

This is a very well referenced opinion article on rare diseases and orphan products including historical and current activities that have led to an increased global emphasis on rare diseases research and orphan products development. The article highlights several of the extremely important aspect of research and development for products for rare diseases - collaboration and coordination of activities. Often, the coordination is led by the leadership of the patient advocacy groups. Since very few research locations have sufficient patient populations to initiate patient recruitment sufficient to open and complete the study, a critical mass of investigators must be established from USA and international research sites. Likewise, patients and patient advocacy groups are now recognized key partners in the research continuum facilitating the recruitment of patients and providing active liaison services with the academic research community,

biopharmaceutical industry, media, Government research and regulatory agencies, and the public.

The article highlights several rare diseases requiring coordinated activities leading to research advances for several rare diseases, e.g., Spinal Muscular Atrophy, Charcot-Marie-Tooth disease, Giant Axonal Neuropathy, Sanfilippo syndrome. These disorders have unique requirements in research design and initiation of clinical trials with appropriate plans for data collection and analyses. The requirements necessitate early and constant contact with the regulatory agencies to reach agreement on biomarkers and clinical or surrogate endpoints for the study, the number of patients required for the study or clinical trial, and the analyses of data to be used to establish the safety and efficacy of the product prior to patient and physician access for patient care. This emphasis on expanded interactions with regulatory agencies has been presented in the article and is particularly important for consideration by the reader as FDA has added many unique regulatory approaches to product review, such as, priority and expedited review and approval of products, fast track review, and breakthrough therapy designation. It is important to understand the value of these regulatory programs and benefits accompanying these products in the research and review stages of product development.

The authors' opinion article indicates one of the great barriers to the development of orphan products has been the financial risk of developing a product for a disease with very small patient 
populations of potential users. The collaborative method of research and development will spread the financial risk over many partners especially in the pre-clinical and early clinical stages of development. For some rare diseases, industry partnerships have been easier to obtain after certain milestones have been exceeded and the likelihood of clinical success is apparent with limited or relative toxicity expected. Reaching these milestones have been reported as significant in the decision making process. For most rare diseases, sharing of global resources remains a powerful incentive for biopharmaceutical industry participation.

The authors conclude with suggested future activities including the dissemination of information to patients and clinicians about novel treatments of rare diseases with selected sub-population of patients with specific genetic mutations. Also, the authors suggest a continued and expanded centralization of many of the rare disease activities including the development of an informatics driven initiative. The authors provide a hopeful view of the future based on even greater global coordination and collaboration offered by centralized sources of information and readily available shared resources from multiple resources in the public and private sectors.

Competing Interests: No competing interests were disclosed.

\section{I confirm that I have read this submission and believe that I have an appropriate level of expertise to confirm that it is of an acceptable scientific standard.}

Author Response 02 Mar 2015

Sean Ekins, Collaborative Drug Discovery, Inc., Burlingame, CA, USA

We would like to thank you for taking the time to review and provide positive comments. It is very much appreciated!

Competing Interests: None

Reviewer Report 18 November 2014

https://doi.org/10.5256/f1000research.5946.r6611

(C) 2014 Meanwell N. This is an open access peer review report distributed under the terms of the Creative Commons Attribution License, which permits unrestricted use, distribution, and reproduction in any medium, provided the original work is properly cited.

\section{Nicholas Meanwell}

Department of Chemistry, Bristol Myers Squibb Research and Development, Wallingford, CT, USA

This is a well-written and articulate article advocating collaborative research and organizational approaches to develop drugs with the potential to treat rare diseases. The case for collaboration is thoughtfully developed and the authors make compelling arguments. I fully sympathize with the contentions laid out in the article and this piece will be a valuable addition to the literature. 
Competing Interests: No competing interests were disclosed.

I confirm that I have read this submission and believe that I have an appropriate level of expertise to confirm that it is of an acceptable scientific standard.

Author Response 02 Mar 2015

Sean Ekins, Collaborative Drug Discovery, Inc., Burlingame, CA, USA

Thank you for your review and support of this article, it is greatly appreciated.

Competing Interests: None

The benefits of publishing with F1000Research:

- Your article is published within days, with no editorial bias

- You can publish traditional articles, null/negative results, case reports, data notes and more

- The peer review process is transparent and collaborative

- Your article is indexed in PubMed after passing peer review

- Dedicated customer support at every stage

For pre-submission enquiries, contact research@f1000.com 